\title{
Identificación Molecular de Salmonella Typhimurium en Cuyes al Primer Parto mediante la Técnica de PCR Múltiple
}

\author{
Molecular Identification of Salmonella TyPhimurium and EnTERITIDIS IN Guinea \\ Pigs at First Parturition by Multiplex PCR \\ Ana Chero O. ${ }^{1}$, Raúl Rosadio A. ${ }^{1}$, Geraldine Marcelo M. ${ }^{1}$, Gerardo Díaz O. ${ }^{1}$, \\ Ronald Jiménez A. ${ }^{3}$, Yenny Castro G. ${ }^{1}$, Lenin Maturrano H. ${ }^{1,2,4}$
}

\section{Resumen}

\begin{abstract}
El estudio tuvo por objetivo identificar el serotipo de los aislados sospechosos de Salmonella spp de cuyes reproductoras en muestras recolectadas dentro de la semana del primer parto con el fin de detectar animales portadores de la bacteria. Los cuyes se encontraban clínicamente sanos y provenían de un criadero comercial de la zona de Pachacamac, Lima, Perú, sin registro de brote de salmonelosis desde hace cuatro años. Se evaluaron 272 muestras pareadas de hisopados rectales y vaginales usando protocolos microbiológicos estandarizados. Las cepas aisladas fueron evaluadas mediante pruebas bioquímicas y se procedió a la extracción de ADN de los aislados sospechosos de Salmonella spp. Posteriormente, estas muestras fueron analizadas mediante la técnica de PCR múltiple para detectar la presencia de los genes invA, prot6E y fliC específicos de Salmonella spp, Salmonella Enteritidis y Salmonella Typhimurium, respectivamente. Ocho animales (12 hisopados) resultaron positivos a Salmonella spp. Los 12 aislados amplificaron al gen invA (Salmonella spp). De estos, 10 amplificaron para el gen fliC (Salmonella Typhimurium) y ninguno amplificó el gen prot6E (Salmonella Enteritidis). Los resultados confirmaron que Salmonella Typhimurium es el patógeno predominante en cuyes reproductoras al primer parto en esta granja de crianza comercial.
\end{abstract}

Palabras clave: cuyes; reproductoras primerizas; Salmonella; PCR múltiple

\footnotetext{
${ }^{1}$ Laboratorio de Microbiología y Parasitología Veterinaria, ${ }^{2}$ Laboratorio de Zootecnia y Producción Agropecuaria, Facultad de Medicina Veterinaria, Universidad Nacional Mayor de San Marcos, Lima, Perú

${ }^{3}$ Estación Experimental del Centro de Investigación IVITA - El Mantaro, Facultad de Medicina Veterinaria, Universidad Nacional Mayor de San Marcos, Huancayo, Perú

${ }^{4}$ E-mail: lenin.maturrano@gmail.com
}

Recibido: 18 de mayo de 2016

Aceptado para publicación: 31 de marzo de 2017 
The aim of the study was to identify serotypes of suspicious isolates of Salmonella spp from breeding guinea pigs in samples collected within the first week of parturition to detect animals carrying the bacteria. The guinea pigs were clinically normal and reared in a commercial farm in Pachacamac, Lima, Peru. The farm was free of Salmonella outbreaks in the last four years. A total of 272 paired samples consisting in rectal and vaginal swabs per animal were collected and analyzed using standardized microbiological protocols. The DNA was extracted from suspected isolates of Salmonella sp and then these samples were analyzed by multiplex PCR to detect the presence of invA, prot6E and fliC genes which are specific for Salmonella spp, Salmonella Enteritidis and Salmonella Typhimurium respectively. Eight animals (12 swabs) were positive to Salmonella spp. All 12 isolates amplified invA (Salmonella spp), 10 of them amplified the fliC gene (Salmonella Typhimurium) and none the prot6E gene (Salmonella Enteritidis). The results confirmed Salmonella Typhimurium as the predominant pathogen in breeding guinea pigs at first parturition in the commercial farm.

Key words: guinea pigs; females at first parturition; Salmonella; multiplex PCR

\section{INTRODUCCIÓN}

El cuy (Cavia porcellus) es una especie consumida tradicionalmente por el poblador andino y, en muchos casos, es la base de su economía doméstica, pues la especie tiene grandes cualidades alimenticias y productivas. Además, es un animal rústico de ciclo de vida corto, por lo que puede ser criado a bajo costo (Ordoñez, 2003), adaptándose a zonas frías y cálidas (Chauca, 1997).

La producción de cuyes ha cambiado de crianza familiar a comercial. Sin embargo, se sabe que el índice de producción en cuyes se ve mermada por la presencia de enfermedades, como es el caso de la salmonelosis. Bacterias del género Salmonella son comúnmente aisladas de cuyes y su presencia está asociada a un amplio rango de morbilidad y mortalidad en estos animales (Pivnick et al., 1966). Esta enfermedad afecta a todos los estratos etarios y normalmente se relaciona con eventos de estrés, pudiendo alcanzar mortalidades de hasta $95 \%$ y morbilidad entre 0.9 y $53 \%$, ocasionando signos clínicos muy variados (Morales et al., 2007). Se dispone de un reporte sobre un brote de salmonelosis ocasionada por Salmonella Typhimurium, que afectó a un criadero de 5000 cuyes causando una mortalidad de 100 animales por día (Morales et al., 1995).

Salmonella se engloba dentro de la familia Enterobacteriaceae y su hábitat principal es el tracto intestinal del hombre y los animales. Los miembros de este género destacan por su gran capacidad de adaptación, lo que les permite infectar a un amplio rango de hospedadores. De acuerdo a la nomenclatura actual, el género Salmonella está conformado por dos especies: $S$. enterica y $S$. bongori. S. enterica está dividida en seis subespecies (enterica, salamae, arizonae, diarizonae, houtenae e indica). Se han descrito 2579 serovariedades de Salmonella, perteneciendo la mayoría de ellas a $S$. enterica subsp enterica, serotipo responsable de infecciones en humanos y animales de abasto (Grimont y Weill, 2007; OIE, 2010).

Los dos serotipos más frecuentemente aislados de cuyes son Salmonella Typhimurium y Salmonella Enteritidis (Fish et al., 1968; Morales, 2012; Bartholomew et al., 2014). Pérez (1975) reportó en cuyes sin 
evidencia de signos clínicos la presencia de $1.9 \%$ de positivos a Salmonella Typhimurium en el departamento de Lima. Ortega et al. (2015) tomó muestras de hisopados vaginales dentro de las 24 horas del parto, encontrando 11 cuyes positivos a Salmonella spp en una población de 129 hembras con historia de mortinatos. En forma similar, Morales (2012), a partir de hisopados rectales de 38 reproductores machos, los cuales iban a ser introducidos en el distrito de San Marcos, Ancash (en ese momento libre de salmonelosis en centros de crianza familiar comercial), aisló 60 cepas bacterianas, de las cuales 10 resultaron ser Salmonella Typhimurium.

La amplificación in vitro de ADN mediante la técnica de reacción en cadena de la polimerasa (PCR) es una herramienta útil en el diagnóstico microbiológico (Malorny et al., 2003a). Existen métodos de PCR para detectar cepas de Salmonella mediante secuencias específicas de genes como marcadores (Manzano et al., 1998). El gen invA contiene secuencias únicas para Salmonella (Rahn et al., 1992), de allí que su amplificación ha sido reconocida como un estándar internacional para la detección de Salmonella (Malorny et al., 2003b). Asimismo, el gen fliC codifica la mayoría de los componentes del flagelo de Salmonella enterica serovar Typhimurium (Aldridge et al., 2006).

Salmonella Enteritidis alberga en su genoma un plásmido único de virulencia de $60 \mathrm{~kb}$ (Chu et al., 1999). Este plásmido posee un gen llamado prot $6 E$, el cual probablemente codifica una proteína de superficie única fimbrial específica a Salmonella Enteritidis (Clavijo et al., 2006). Actualmente, se viene implementando una técnica molecular (PCR múltiple) empleando estos tres genes, para la identificación de Salmonella spp, Typhimurium y Enteritidis (Marcelo, 2015).

La salmonelosis usualmente requiere de la intervención de algún factor que genere estrés en el animal (Ramírez, 1972; Radostits et al., 2002). El parto, al igual que la preñez y la lactancia son considerados como factores estresantes para el animal (Radostits et al., 2002), de modo que, si se establece la presencia del agente infeccioso, se podrían generar condiciones favorables para el desarrollo de la salmonelosis después del primer parto. Por ello, el presente estudio tuvo como objetivo evaluar la presencia de Salmonella Typhimurium y Enteritidis en cuyes hembras primerizas aparentemente sanas de un centro de crianza comercial del distrito de Pachacamac, Lima.

\section{Materiales y Métodos}

\section{Lugar del Estudio}

La toma de muestras tuvo lugar en un criadero comercial sin registro de brote de salmonelosis en los últimos cuatro años. La granja está ubicada en el distrito de Pachacamac, Lima, Perú. El muestreo se realizó entre mayo a septiembre de 2015 y el procesamiento de las muestras se llevó a cabo en el laboratorio de genética y biología molecular de la Facultad de Medicina Veterinaria de la Universidad Nacional Mayor de San Marcos, Lima.

Los cuyes eran criados en pozas, donde se colocaba un macho por 10 hembras bajo un sistema de empadre continuo.

\section{Toma de Muestras}

Se realizaron hisopados vaginales y rectales en cuyes reproductoras clínicamente sanas, seleccionándose una hembra por poza. La toma de las muestras fue dentro de la primera semana posparto. El hisopado vaginal se realizó con hisopos estériles, previa limpieza de la zona con suero fisiológico, en tanto que el hisopado rectal se realizó frotando el hisopo contra la pared de la cavidad rectal. Los hisopos fueron almacenados en tubos con agua peptonada tamponada (APT) y conservados a $4{ }^{\circ} \mathrm{C}$ para su inmediato transporte al laboratorio. 
Cuadro 1. Cebadores empleados en la PCR Múltiple para identificar al género Salmonella y Salmonella serovar Typhimurium y Enteritidis (Jamshidi et al., 2010)

\begin{tabular}{|c|c|c|c|}
\hline $\begin{array}{l}\text { Especie / } \\
\text { serovar }\end{array}$ & Gen & $5 \stackrel{\text { Secuencia }}{\longrightarrow} 3$, & $\begin{array}{c}\text { Tamaño } \\
(\mathrm{pb})\end{array}$ \\
\hline Salmonella spp & $\operatorname{inv} \mathrm{A}$ & $\begin{array}{l}\text { GTGAAATTATCGCCACGTTCGGGCAA } \\
\text { TCATCGCACCGTCAAAGGAACC }\end{array}$ & 284 \\
\hline $\begin{array}{l}\text { Serovar } \\
\text { Typhimurium }\end{array}$ & $f l i \mathrm{C}$ & $\begin{array}{l}\text { CGGTGTTGCCCAGGTTGGTAAT } \\
\text { ACTCTTGCTGGCGGTGCGACTT }\end{array}$ & 559 \\
\hline $\begin{array}{l}\text { Serovar } \\
\text { Enteritidis }\end{array}$ & prot6E & $\begin{array}{c}\text { ATATCGTCGTTGCTGCTTCC } \\
\text { CATTGTTCCACCGTCACTTTG }\end{array}$ & 185 \\
\hline
\end{tabular}

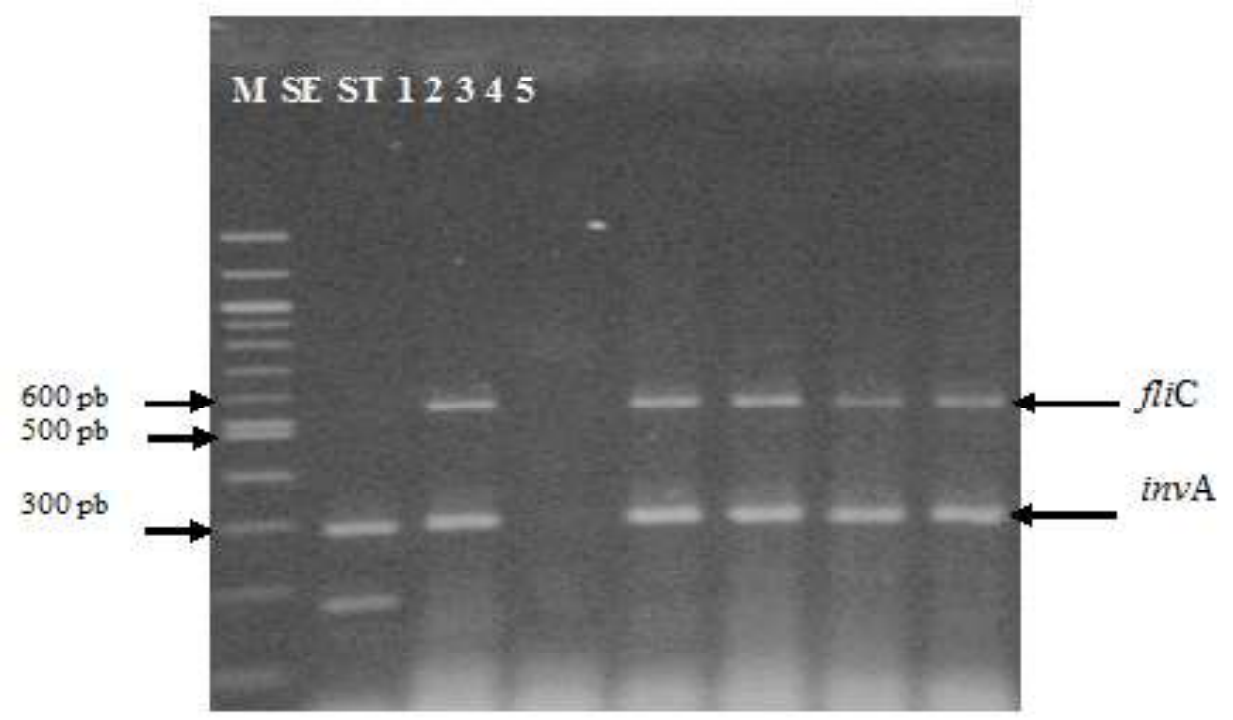

Figura 1. Productos de PCR múltiple de los aislamientos de Salmonella Typhimurium. M, Marcador de peso molecular 100 pb DNA ladder; SE, control positivo de Salmonella Enteritidis (ATCC 13076); ST, control positivo de Salmonella Typhimurium (ATCC 14028). Carril 1, muestra negativa; carriles 2 al 5, aislados positivos a Salmonella serovar Typhimurium $(559 \mathrm{pb})$

\section{Procesamiento de las Muestras}

Se evaluaron 272 muestras pareadas (hisopado vaginal y rectal por animal).

Los hisopados contenidos en caldo APT fueron incubados a $37{ }^{\circ} \mathrm{C}$ por $18 \mathrm{~h}$. Posteriormente $1 \mathrm{ml}$ de cada muestra fue cultiva- da en caldo Rappaport Vassiliadis Soya (RVS) siguiendo la proporción de 1:9 e incubados a $42{ }^{\circ} \mathrm{C}$ por $24 \mathrm{~h}$. Luego, se cultivó en agar Xilosa Lisina Desoxicolato (XLD) por $24 \mathrm{~h}$, para seleccionar a los aislados sospechosos y ser sometidos a cinco pruebas bioquímicas: agar hierro lisina (LIA), agar hierro tres 
azúcares (TSI), medio SIM, agar urea, agar citrato de Simmons. El método microbiológico utilizado se basó en protocolos del Laboratorio de Global Salm Surv de la Organización Mundial de la Salud (WHO, 2010), siguiendo la norma ISO:6579 (2007)

La extracción de ADN se hizo de los aislados sospechosos utilizando un kit de extracción de ADN bacteriano GF-1 (Vivantis, EEUU). Se siguió el protocolo de Marcelo (2015), donde se realizó una PCR múltiple utilizando tres pares de cebadores, los cuales codifican las secuencias de los genes invA, fliC y prot6E para la identificación de género como de los serotipos Typhimurium y Enteritidis, respectivamente (Cuadro 1). Los productos de PCR múltiple fueron separados mediante electroforesis en gel de agarosa al $2 \%$ en la cámara de electroforesis horizontal. Para evidenciar las bandas de ADN amplificadas, el gel fue teñido con bromuro de etidio y visualizado en un transiluminador de luz ultravioleta (Cleaver Scientific).

\section{Resultados}

Salmonella spp fue aislada en el 2.9\% de los cuyes (8/272). Ocho cuyes fueron positivos en el hisopado rectal y de estos, cuatro fueron, además, positivos en hisopado vaginal. Los 12 aislados fueron sometidos al PCR múltiple, donde amplificaron el gen invA correspondiente al género Salmonella. De estos aislados, 10 resultaron positivos a Salmonella Typhimurium (Figura 1) y los 2 restantes no pertenecían al serovar Typhimurium ni al serovar Enteritidis (Cuadro 2).

\section{Discusión}

Las reproductoras en estudio provinieron de un solo criadero, donde según información del criador no presentaban brotes de salmonelosis desde hace cuatro años; sin embargo, ocho cuyes $(2.9 \%)$ resultaron po- sitivas a Salmonella spp mediante pruebas bacteriológicas. Esta frecuencia es similar al estudio de Ortega et al. (2015), quienes encuentran positivos a Salmonella al $2.3 \%$ de cuyes hembras recién paridas y sin antecedentes de problemas reproductivos.

La presencia de Salmonella spp en los animales, especialmente del serotipo Typhimurium, podría indicar la presencia de cuyes que estarían actuando como portadores del agente patogénico $\mathrm{y}$, a la vez, como diseminadores para el desencadenamiento de brotes de salmonelosis. Dado los resultados obtenidos, se sugiere que estos animales podrían ser portadores asintomáticos del serotipo Typhimurium en bajos porcentajes.

En el Perú aún no ha sido reportado el serovar Salmonella Enteritidis en cuyes; sin embargo, fue aislado de un brote en cuyes para producción en Canadá, donde morían 20 a más animales por día (Fish et al., 1968) y en cuyes criados como mascotas en EEUU (Bartholomew et al., 2014). En ambos casos, los propietarios fueron infectados por este serovar, determinando así el riesgo de transmisión del animal al ser humano por contacto directo con animales aparentemente sanos, así como con animales enfermos.

Los resultados del presente estudio confirman la presencia de Salmonella Typhimurium como el serovar predominante en cuyes reproductoras, tal como fue reportado por Pérez (1975) en una hembra adulta aparentemente sana de un criadero sin antecedente de brote. Okewole et al. (1989) aislaron Salnonella Typhimurium del útero de cuyes, y al inocular estos aislados por vía venosa desarrollaron lesiones en útero; asimismo, también se reporta su aislamiento de la glándula mamaria (Pérez, 1975; Ramírez, 1972; Matsuura et al., 2010). En el presente estudio, es posible que las hembras hayan podido superar la infección tiempo atrás y estuvieran comportándose como portadoras; por ello, la expulsión del agente por el tracto reproductivo, encontrado en los hisopados vaginales. 
En las pozas de la granja en estudio había una diversidad de edades y de número de partos entre las hembras, de allí es que no todas las hembras positivas a Salmonella Typhimurium hayan estado expuestas a este agente en un momento dado, pero al compartir el mismo espacio con hembras portadoras se haya propiciado la transmisión de la bacteria. Además, los criaderos usualmente introducen reproductores para la mejora de la producción; sin embargo, no siempre se toman muestran de los animales a ser introducidos. Así se tiene el caso de cuyes introducidos a centros de sistema de crianza familiar-comercial en el distrito de San Marcos donde se evaluaron los de machos reproductores que iban a ser introducidos aislándose Salmonella Typhimurium (Morales, 2012). Estas experiencias remarcan la importancia de análisis previos de animales a ser introducidos en las granjas.

\section{Conclusiones}

- Salmonella Typhimurium fue el serotipo predominante de Salmonella spp en hembras de primer parto y sin signos clínicos de enfermedad, en un criadero de cuyes de la zona de Pachacamac, Lima.

- El porcentaje de prevalencia de Salmonella sp en hisopados vaginales y rectales fue de $2.9 \%(8 / 272)$.

\section{Agradecimientos}

Los autores expresan su agradecimiento al Programa Nacional de Innovación para la Competitividad y Productividad - Innóvate Perú, fuente financiadora del Proyecto «Desarrollo de una vacuna para el control y prevención de la salmonelosis en la producción de cuyes», Contrato $N^{\circ} 362$-PNICP-PIAP2014. A los propietarios del centro de crianza de cuyes, Sres. Eduardo López y Yenny Castro, por brindar las facilidades para realizar el estudio. A Laura Córdova, Gerardo Díaz y Geraldine Marcelo por su apoyo incondicional durante las tomas de muestra y a Rocío
Rimac por su aporte en el desarrollo del estudio.

\section{Literatura Citada}

1. Aldridge P, Gnerer J, Karlinsey JE, Hughes KT. 2006. Transcriptional and translational control of the Salmonella fliC gene. J Bacteriol 188: 4487-4496.

2. Bartholomew M, Heffernan R, Wright J, Klos R, Monson T, Khan S, Trees E, et al. 2014. Multistate outbreak of Salmonella enterica serotype Enteritidis infection associated with pet guinea pigs. Vector Borne Zoonotic Dis 14: 414-421. doi: 10.1089/vbz.2013.1506

3. Chauca L. 1997. Producción de cuyes (Cavia porcellus). Lima: Organización de las Naciones Unidas para la Agricultura y la Alimentación. $80 \mathrm{p}$.

4. Chu C, Hong S, Tsai C, Lin W, Liu T, Ou J. 1999. Comparative physical and genetic maps of the virulence plasmids of Salmonella enterica serovars Typhimurium, Enteritidis, Choleraesuis, and Dublin. Infect Immun 67: 2611-2614.

5. Clavijo R, Loui C, Andersen G, Riley $L, L u S$. 2006. Identification of genes associated with survival of Salmonella enterica serovar Enteritidis in chicken egg albumen. Appl Environ Microbiol 72: 1055-1064. doi: 10.1128/AEM.72.2. 1055-1064.2006

6. Fish NA, Fletch AL, Butler WE. 1968. Family outbreak of salmonellosis due to contact with guinea pigs. Can Med Assoc J 99: 418-420

7. Grimont PA, Weill FX. 2007. Antigenic formulae of the Salmonella serovars. $9^{\text {th }}$ ed. Paris, France: WHO Collaborating Centre for Reference and Research on Salmonella. $166 \mathrm{p}$.

8. Habermann R, Williams, F Jr. 1958. Salmonellosis in laboratory animals. J Ntl Cancer Inst 20: 933-947.

9. [ISO] International Organization for Standardization. 2012. ISO 6579:2002. Microbiology of food and animal feeding 
stuffs - Horizontal method for the detection of Salmonella spp. [Internet] Disponible en: http://www.iso.org/iso/ catalogue_detail.htm?csnumber $=29315$

10. Jamshidi A, Kalidari G, Hedayati M. 2010. Isolation and identification of Salmonella Enteritidis and Salmonella Typhimurium from the eggs of retail stores in Mashhad, Iran using conventional culture method and multiplex PCR assay. J Food Safety 30: 558-568. doi: 10.1111/j.17454565.2010.00225.x

11. Malorny B, Hoorfar J, Hugas M, Heuvelink A, Fach P, Ellerbyoek L, Bunge $C$, et al. 2003a. Interlaboratory diagnostic accuracy of a Salmonella specific PCR-based method. Int J Food Microbiol 89: 241-249. doi: 10.1016/ S0168-1605(03)00154-5

12. Malorny B, Hoorfar J, Bunge C, Helmuth R. 2003b. Multicenter validation of the analytic accuracy of Salmonella PCR: toward an international standard. Appl Environ Microbiol 69: 290-296. doi: 10.1128/ AEM.69.1.290-296.2003

13. Manzano M, Cocolin L, Astori G, Pipan C, Botta G, Cantoni C, Comi G 1998. Development of a PCR microplate-capture hybridization method for simple, fast and sensitive detection of Salmonella serovars in food. Mol Cell Probes 12: 227-234. doi: 10.1006/ mcpr.1998.0176

14. Marcelo G. 2015. Identificación de Salmonella Enteritidis y Typhimurium aislada de cuyes mediante la técnica de reacción en cadena de la polimerasa múltiple. Tesis de Médico Veterinario. Lima: Univ Nacional Mayor de San Marcos. $51 \mathrm{p}$.

15. Matsuura A, Morales $S$, Calle S, Ara $M . ~ 2010$. Susceptibilidad a antibacterianos in vitro de Salmonella enterica aislada de cobayos de crianza familiarcomercial en la provincia de Carhuaz. Rev Inv Vet Perú 21: 93-99. doi: 10.15381/rivep.v21i1.355
16. Morales C, Hung A, Alvarado A. 1995. Mortalidad por salmonelosis en cobayos. En: XVIII Reunión científica Anual de la Asociación Peruana de Producción Animal (APPA). Lambayeque.

17. Morales S, Mattos J, Calle S. 2007. Efecto de la muña (Satureja parvifolia) en la dinámica de la infección por Salmonella enterica en cobayos. En: XXX Reunión Científica de la Asociación Peruana de Producción Animal (APPA). Cusco, Perú.

18. Morales $S$. 2012. Patógenos oportunistas por transmisión fecal-oral en cuyes reproductores introducidos al distrito de San Marcos. Científica 9(1): 33-36.

19. [OIE] World Organisation for Animal Health. 2010. Salmonellosis. [Internet]. Disponible en: http://www.oie.int/ fileadmin/Home/eng/Health_standards/ tahm/2008/pdf/2.09.09_salmonellosis.pdf

20. Okewole PA, Uche E, Oyetunde I, Odeyemi P, Dawul PB. 1989. Uterine involvement in guinea pig salmonellosis. Lab Anim 23: 275-277. doi: 10.1258/ 002367789780810518

21. Ordoñez R. 2003. Plan de introducción de la carne de cuy en Lima Metropolitana: estudio de mercado y propuesta empresarial. Tesis de Magíster. Lima: Pontificia Universidad Católica del Perú. $213 \mathrm{p}$.

22. Ortega G, Jiménez R, Ara A, Morales S. 2015. La salmonelosis como factor de riesgo de mortinatalidad en cuyes. Rev Inv Vet Perú 26: 676-681. doi: 10.15381/rivep.v26i4.11203

23. Pérez ZN. 1975. Investigación de salmonelas en cobayos (Cavia porcellus) aparentemente normales. Tesis en de Biólogo. Lima: Univ Nacional Mayor de San Marcos. 19 p.

24. Pivnick H, Stuart P, Walcroft M. 1966. Establishment of a Salmonella-free guinea pig colony. The Can J Comp Med Vet Sci 30: 279-281.

25. Radostits OM, Gay CC, Blood DC, Hinchcliff $K \boldsymbol{K}$. 2002. Tratado de enfermedades del ganado bovino, ovino, caprino y equino. $9^{\mathrm{a}}$ ed. Madrid: McGrawHill. 959 p. 
26. Rahn K, De Grandis S, Clarke R, Mcewen S, Galán JE, Ginocchio C, Curtiss R III, Gyles CL. 1992. Amplification of an invA gene sequence of Salmonella typhimurium by polymerase chain reaction as a specific method of detection of Salmonella. Mol Cell Probes 6: 271-279. doi: 10.1016/ 0890-8508(92)90002-F

27. Ramírez I. 1972. Estudio bacteriológico y epidemiológico de un brote infec- cioso en cobayos (Cavia porcellus). Tesis de Médico Veterinario. Lima: Univ Nacional Mayor de San Marcos. 62 p.

28. WHO Global Foodborne Infections Network. 2010. Laboratory Protocol «Isolation of Salmonella spp from food and animal faeces». $5^{\text {th }}$ ed. [Internet]. Disponible en: http://www.antimicrobialresistance.dk/data/images/protocols/ isolation_of_salm_220610.pdf 